\title{
Can systems immunology lead tuberculosis eradication?
}

Pere-Joan Cardona ${ }^{1 *}$, Martí Català2, Marta Arch ${ }^{1}$, Lilibeth Arias ${ }^{1}$, Sergio Alonso², Paula Cardona $^{1}$, Daniel López ${ }^{2}$, Cristina Vilaplana ${ }^{1}$, Clara Prats ${ }^{2 *}$

${ }^{1}$ Unitat de Tuberculosi Experimental, Fundació Institut d'Investigació en Ciències de la Salut Germans Trias i Pujol, Universitat Autònoma de Barcelona, CIBERES, Badalona, Catalonia. Spain.

2 Departament de Física, Universitat Politècnica de Catalunya-BarcelonaTech, Castelldefels, Catalonia, Spain.

*Corresponding authors: Pere-Joan Cardona (pj.cardona@gmail.com), Clara Prats (clara.prats@upc.edu)

\section{Abstract (100-120 words)}

25 years after the declaration of a Global Emergency by the World Health Organization, tuberculosis (TB) remains a major enemy to the humankind. During this period, much progress has been done to better understand its natural history, revealing its huge complexity, which highlighted the need for implementing systems immunology approaches. Recent advances focused in understanding the role of macrophage subtypes and dendritic cells role, the importance of cytokine balance, and the antigenic repertoire. Identification of early irruption of polymorphonuclear neutrophils and extracellular growth of the bacilli seem to be the most disruptive factors to understand the evolution towards active TB. Their inclusion in future models will provide new tools for the better understanding of the tuberculosis.

\section{Keywords}

Systems biology, Systems immunology, Tuberculosis, Granuloma, Mathematical model, Agent-based model.

\section{Introduction}

Mycobacterium tuberculosis ( $M t b)$ remains the only bacteria able to cause the highest mortality by itself. Tuberculosis (TB) natural history has an extraordinary complexity and, in fact, there are still too many unknowns [1] on the mechanisms underlying it. Although there was a significant increase in new information in the last years because of the entrance of omics, it remains unclear how to interpret and use such information for the understanding of key questions. The last review on TB FAQS [2] is a clear and strong declaration of humility around the issue, showing up to which degree of ignorance we are still immersed since 1993, when World Health Organization declared for the first time in the history a Global Emergency linked to a sole infectious disease. This lack of knowledge and capability for giving response to these questions is the explanation for the current feeling of "trap" in which we are immerse, to the extreme that we are not ashamed to publicly declare that we are searching a "pink swan" [3]. The numbers are crushing because of the global annual stability on the absolute number of new TB cases (around 9 million), the massive amount of deaths (around 1.4 million), the increase on multidrug-resistant cases (about 0.5 million), the slow annual decrease on the incidence (around 1.5\%) and, what is worse, the clear understanding that 
these data come themselves from an epidemiological model [4]. This scenario is in clear contrast with, for instance, the recent success achieved in the case of Ebola. Roughly just after 3 years of the epidemics declared in occidental Africa, a vaccine is available giving a $100 \%$ efficacy of protection [5].

The purpose of this work is to obtain a more thorough understanding of 14 biological phenomena identified at a cellular level that a systems immunology approach would enable to contextualize and quantify in a time/spatial frame. This will provide a better knowledge of the natural history of the $M t b$ infection and will facilitate progress in the fight against TB.

\section{What is the role of looking at TB challenge from the point of view of an "in silico" systems immunology?}

Usually, the systems immunology approach is seen with skepticism by the immense majority of researchers. The complexity of the mathematical language and the theoretical assumptions do not help at all to its understanding and its value to experimental researchers. Even when trying to set multidisciplinary teams [6], the intellectual background of each integrant usually represents a strong handicap for a fluent exchange of ideas. In addition, there are different interests. From one side, experimental researchers want to find new clues and predictions from their work. From the other side, theoretical biologists have a need for new experimental data to confirm their models. All in all, there is a basic point of confluence that will always help both sides: trying to include experimental observations in a relevant time and space frame.

Systems immunology is the right approach for bridging these issues in the context of hostpathogen interactions in infectious diseases, as defended by Kirschner et al [7]. In general, computational models offer a platform where experimental data are integrated and used to interpret observed phenomena. In addition, carefully designed simulation series are appropriate for testing hypothesis, exploring the parameters space with a higher precision and in a wider range than experiments, and predict emergent behaviors. Systems immunology cannot substitute experimental observations, however it is the perfect traveling companion to face TB challenges at this level.

\section{The bottom-line of systems biology approaches}

Davis et al. [6] defines a systems approach as a "broad strategy for understanding how a complex set of interacting components works to produce certain outcomes", giving rise to systems immunology when we deal with the interactions with or between components of the immune system. Systems immunology approaches can make use of different modelling techniques, taking into consideration some common characteristics of the biosystems that are aiming to describe: (1) they are constituted by discrete elements, from chemical signals and molecular structures of the cellular membrane to a population of cells organized in certain structures; (2) their behaviors have stochastic elements; and (3) it is normally necessary to consider a space-time framework in order to understand their dynamics. Continuous models can be used as a first approximation to the whole system and also to describe those parts or components where discrete elements are not relevant. On the contrary, bottom-up approaches are necessary when dealing with the interaction between components, where agent-based models, multiscale approaches and hybrid models reveal strategically interesting.

GranSim: a historical hybrid systems immunology approach to granuloma formation 
GranSim is hybrid model of granuloma dynamics that was released in 2004 by Segovia-Juarez et al [8]. In its original version, it used a combination of a continuous modelling of chemokines with a discrete agent approach of macrophages and $T$ cells in a cellular automata-like environment. This hybrid model has experienced several subsequent modifications and updates to deal with particular questions, as will be detailed in the following section, and it has been used by other groups as a tool for simulating TB host-pathogen interactions in lungs.

\section{A reasonable TB morphological model. Setting a basic phenotypical space-time frame.}

As the main driver in the immune response against TB is the cellular immune response, it is logical to draw it at the cellular scale. Figure 1 tries to roughly include the whole progress in 14 steps that should be taken into account in any systems biology approach for the understanding of this disease. In the next paragraphs we look over the different steps, we revise the most recent systems biology approaches to each of them and we highlight the unknowns that still need to be tackled. Table 1 summarizes these published approaches and relate them with the corresponding steps (1 to 14), providing more technical details such as the kind of model(s) used, if they use GranSim or not, and their main purpose and the variables considered.

\section{The long road towards the alveoli (1)}

The first step is the entrance of the bacilli through an aerosol drop. Even when this step could be considered out of the scope of this review, our lack of understanding makes worthy to consider it, especially taking into account the data recently appeared about the role of the hydrophobicity of the cell wall of $M t b$ in comparison with other mycobacteria and its influence to remain in aerosol droplets [9]. Also, newest data on the aerosol quality and the capacity of these aerosols to hold Mtb bacillary clumps [10] might be relevant to understand the interaction with the alveolar macrophage. At this stage, there is a need for linking the classic data of the frequent observation of TB in the right upper lobes and the periphery of the lung [11] with the respiratory movements and the bronchial tree geometry, taking advantage of newest data on the deposition of particles and with the help of virtual modeling of the lung [12].

\section{The interaction at the alveoli (2)}

There is a lot of information about the interaction of $M t b$ with the alveolar macrophages (AM), mostly because the relative easiness of this model in vitro. Nevertheless, a model that integrates from the interaction with the receptor until the escape of $M t b$ from the phagosome by triggering necrotic factors and inhibiting the apoptotic ones, has not been built yet. Equally, at this level, the interaction with the epithelial cells once the macrophage is destroyed by the growth of the bacilli should be still clarified [13]. In this regard, Drosophila melanogaster appears to be a good model to clarify the interaction of the bacilli with the respiratory and intestinal epithelia [14]. A new recent model built in Netlogo platform has linked the lack of drainage in the alveoli of the upper lobes with the local accumulation of bacilli. This increase in the bacillary charge has to be faced by the new incoming alveolar macrophage, which has been linked with the type of inflammatory response (i.e., monocyte or polymorphonuclear neutrophil (PMN) oriented) [15].

\section{The onset of the granuloma (3\&4)}


It is assumed that each alveolus holds a unique $\mathrm{AM}$ and that its replacement is a physiological phenomenon. AM must phagocyte all the particles and pathogens carried by the inhaled air. Thus, its substitution must be considered as normal. It is thought that, after a sort of interaction with the epithelial cells, interstitial AM are the ones that replace damaged AM. This is a very important point in order to keep the tightness of the alveoli not to disrupt the low tensional surface induced by the constant secretion of surfactant that avoids its collapse. Triggering a local inflammatory response and thus breaking the endothelial integrity to allow the entrance of blood cells and plasma is a not well understood process. This has to be well tuned as it represents the loss of the alveoli functionality. Probably this takes place once several neighbor AM from the same acini (for anatomical reasons) are necrotized [3]. The local accumulation of chemokines, surely helped by the stimulation of epithelial cells, must lead to a critical point that stimulates the entrance of blood cells and plasma, ruining the acini. As mentioned above, inflammatory response induces two sorts of granulomas, the one in which there is a monocytic predominance (proliferative) or a PMN based one (exudative). This phenomenon has been recently defined after carefully studying the murine model with the C3HeB/FeJ strain, also known as Kramnik model [16], [17]. Regarding the monocytic infiltration and its transformation in macrophages, they can differentiate in M1 or M2 class, a fact that is relevant due its differential capacity to react against the bacilli, as recently pointed in a mathematical model [18].

\section{The interaction with the regional lymph node (5)}

With the inflammatory response and destruction of the alveoli functionality, the lymphatic drainage starts propelled by the overpressure caused by the plasmatic entrance. Bacilli are drained freely towards the local lymph nodes at the very beginning, and by the newly induced dendritic cells (DC) afterwards. Once there, they are phagocytosed by the first line of macrophages disposed at the narrow subcapsular sinus [19]. Those that are not filtered are finally phagocytosed by DCs. This aspect was addressed experimentally raising the concept of two compartments at the lymphatic tissue: the infected one and the proliferative one, respectively [20], a process that should merit a deep modelling exercise. DCs will then trigger a lymphocytic proliferation depending on the inflammatory media in which they are immersed. Acute mediators, a complex mixture of IL-1, TNF- $\alpha$, IL-6, IL-10, prostaglandins and leukotriens, to cite some of them, together with cytokines like IL-2, IL-4, IL-12, IL-13, IFN- $\gamma$ and TGF- $\beta$ will determine the sort of CD4 T (Th1, Th2 or Th17 basically) together with CD8 T, Treg and $B$ cells. This is a very complex process that was initially addressed and is constantly updated by the GranSim model [8]. In one of its latest versions, as a part of a multicompartment hybrid model, it explicitly accounts for the DC role on the interaction with the regional lymph node [21], [22]. This update has been raised on the selection of antigens and the selection of memory $T$ cells that would be able to better control the infection [22].

\section{The relation of the granuloma with the adaptive immune response (6 to 8)}

The sort of lymphocytic population triggered and proliferated at the lymph nodes will reach the lung parenchyma, pumped by the right ventricle. Basically, Th1 cells will detect and activate infected macrophages through IFN- $\gamma$ and will kill the bacilli. This action can be also induced by CD8 cells. On the other hand, this action can be moderated by Th2 cells by inducing IL-4 and IL-10. Tregs also can help this anti-inflammatory response by secreting IL-10 and TGF$\beta$ and through direct cell to cell interaction. Equally, activated macrophages tend to suppress the action of T cells, raising the typical "doughnut" form, also reproduced by some models [23], [24], being able to stop the local proliferation of lymphocytes (if this takes places, since 
it is a controversial issue). Activated macrophages also hold survived bacilli that, entering into dormancy, avoid the destruction. They also phagocyte the cellular debris of death cells, finally becoming foamy macrophages (FM) [25]. FM can either be locally necrotized or drained towards the bronchi escalator [26]. In that case, they may be trapped in the parenchyma and develop a local new foci, or they can reach further and become part of the drained alveolar fluid. Th17 lymphocytes will be responsible for attracting more PMNs. This production would be highly biased by the initial induction of a PMN-based granuloma at the beginning of the infection. The enormous effort done in omics study and the huge information already obtained from it, even coming from blood sampling in humans or from the macaque model, has to push to new algorithms to understand its complexity and finally include them in models like GranSim, where there is a constant update with the new information obtained [21], [24], [27]-[30].

\section{The balance on the size of the granuloma (9)}

Induction of TB is characterized by the formation of a large enough lesion able to be seen in a chest $X$ ray, i.e., of around $10 \mathrm{~mm}$. Recent data on the $\mathrm{C} 3 \mathrm{HeB} / \mathrm{FeJ}$ shows an exponential growth of the granuloma thanks to the massive infiltration of PMNs that fuels the extracellular growth of the bacilli sooner than the previous concept that relegated this phenomenon to liquefacted and cavitated lesions [31]. This phenomenon is helped by the drainage of infected FM that appear heavily surrounded by PMNs, pushing a peripheral growth of the lesion [16]. This lead to think on the coalescence between lesions and raised the TB "bubble model" [32], which demonstrates that the induction of a large lesion requires an exponential growth of the lesion (as seen by the one infiltrated with PMNs), a constant induction of peripheral daughter new foci, and the confluence of all these lesions. This is a very important factor, as usually PMNs role in the TB granuloma is not addressed, even in the GranSim model [8] or in other systems biology approaches [18], [23], [33], [34], which considering an unknown role of these cells, do not include them in their assumptions. Interestingly, data from human lesions obtained from the pre-antibiotic era, clearly point the presence of two sorts of lesions: the proliferative ones, with a controlled size and encapsulated, macrophage-based; and the exudative ones, with a predominium of PMNs, that are the ones that enlarge, become liquefacted and cavitated, or develop large pneumonic processes, both are characteristic lesions of active TB [15].

New tools like the monitoring of lesions in the macaque model thanks to the TAC-PET [35] will definitely help to understand the growth process of the lesions. In fact, the use of Mtb bar-coded strains will give a clear clue on it [36].

\section{The encapsulation process (10)}

The growth of lesions has a physical constraint, which is the interlobular septae that divides the lung parenchyma [37]. This was first described in the minipig model [38], and also takes place in mice when the lesion touches the pleura. The role of fibroblasts and a balanced antiinflammatory immune response (both triggered by Th2 or Treg cells) might help the encapsulation, induction of miofibroblasts and control of the size of the lesion. The role of TGF- $\beta$ and fibrosis has recently been addressed in the GranSim model [28], while the encapsulation process has been explored from the modelling perspective in [15].

The airway drainage of the bacilli, a way to the gastrointestinal or to the parenchyma (11 and 12) 
Thanks to the bronchial drainage of FM, bacilli have the opportunity to reach the alveolar fluid. Most of them will be drained towards the gastrointestinal tract. Actually, a well-known way to diagnose TB in children, who do not develop cavitated lesions, is through gastric lavage. However, some of the bacilli will become part of the aerosols induced at the final bronchi, thanks to their constant expansion and retraction with the respiratory movements. Even when there is some experimental data and modeling on this aspect, this should be integrated in a deeper model for better understanding the aerosol movements in the lung, as pointed above. Bar-coded Mtb strains [36] will clearly give a clue on it.

\section{The way back to the alveoli through the capillary net (13)}

Once bacilli reach the lymph node it is reasonable to predict that some of them might escape from both macrophages and DCs, which may move towards the efferent vessels that reach the cava vein, the right auricle and ventricle, and are pumped again to the lung parenchyma. In this case the possibility to reach previously infected foci is higher, as there is a higher irrigation. This phenomenon was highlighted in the zebra fish model [39], but the actual relevance and the probability that these bacilli might induce new foci has not been clarified yet. It is logical to suppose that clumped bacilli would have a better chance to induce a blockage in the capillary end, disrupt the endothelial parenchyma and enter the alveoli as seen experimentally [40]. Remaining bacilli will reach the left ventricle and induce extrapulmonary lesions.

\section{The second systemic wave (14)}

With the consolidation of the granulomas, and especially in the enlarged ones, new processes take place. One of them is the progressive formation of necrosis and the appearance of hypoxic zones. This aspect has been addressed in several models due to its interest in the understanding of the mode of action of chemotherapy [23], [34], [41]. Another important process is the neo vascularization. This has a special interest because of its fragility, which will facilitate the direct entrance of the bacilli in the blood and its extrapulmonary distribution through the left ventricle.

\section{Discussion}

Since 2004, with the building of the GranSim TB model by the group of Kirschner [8], the understanding of the natural history of TB has experimented a new impulse. In the last two years, this group has greatly updated it by including the role of several cytokines, DCs and fibroblasts. It is expected that they will also include PMNs, the local dissemination of lesions and the encapsulation process in order to have a better model. GranSim and other systems biology approaches have made great progress in the understanding of some of the stated 14 steps, as summarized in Table 1. Furthermore, it will be important to build new models to better understand the dynamics of the infected aerosols and the possibilities of the bacillus entrance in the capillary net to reach extrapulmonary sites.

\section{Conclusion}

Identification of early irruption of the PMNs and extracellular growth of the bacilli seem to be the most disruptive factors to understand the evolution towards active TB that have appeared 
in the last two years. Their incorporation in the current models will surely be a hallmark in understanding the progression towards active TB and provide new tools to fight against it.

\section{Acknowledgements}

Plan Nacional I+D+I co-financed by ISCIII-Subdirección General de Evaluación and Fondo-EU de Desarrollo Regional (FEDER) and co-funded through the Projects PI11/01702, PI14/01038 and MS 13/00174, Ramon y Cajal program through grant RYC-2012-11265, and the contracts CP13/00174 and IFI14/00015. Centro de Investigación Biomédica en Red de Enfermedades Respiratorias (CIBERES). The Experimental Tuberculosis Unit is accredited by the Catalan Agency for Management of University and Research Grants with code 2017 SGR500 and the IGTP is member of the CERCA network of institutes. The funders have no role in study design, data collection and analysis, decision to publish, or preparation of the manuscript. To Júlia Gallardo, for drawing such an excellent figure!

\section{References}

[1] T.H.M. Ottenhoff, "The knowns and unknowns of the immunopathogenesis of tuberculosis", Int. J. Tuberc. Lung Dis., vol. 16, no. 11, pp. 1424-1432, 2012.

[2] K. M. Guinn and E. J. Rubin, "Tuberculosis: Just the FAQs," MBio, vol. 8, no. 6, pp. 114, 2017.

[3] P.-J. Cardona, "What We Have Learned and What We Have Missed in Tuberculosis Pathophysiology for a New Vaccine Design: Searching for the 'Pink Swan,'” Front. Immunol., vol. 8, no. May, p. 556, 2017.

[4] World Health Organization, Global Tuberculosis Report 2017. Geneva, Switzerland: WHO, 2017.

[5] F. A. Plummer and S. M. Jones, "The story of Canada's Ebola vaccine," C. Can. Med. Assoc. J., vol. 189, no. 43, pp. E1326-E1327, Oct. 2017.

[6] M. M. Davis, C. M. Tato, and D. Furman, "Systems immunology: Just getting started," Nat. Immunol., vol. 18, no. 7, pp. 725-732, 2017.

[7] D. Kirschner, E. Pienaar, S. Marino, and J.J. Linderman, "A review of computational and mathematical modeling contributions to our understanding of Mycobacterium tuberculosis within-host infection and treatment", Curr. Opin. Syst. Biol., vol. 3, pp. 170-185, 2017.

[8] J. L. Segovia-Juarez, S. Ganguli, and D. Kirschner, "Identifying control mechanisms of granuloma formation during M. tuberculosis infection using an agent-based model.," J. Theor. Biol., vol. 231, no. 3, pp. 357-76, Dec. 2004.

[9] M. Jankute, V. Nataraj, O. Y. C. Lee, H. H. T. Wu, M. Ridell, N. J. Garton, M. R. Barer, D. E. Minnikin, A. Bhatt, and G. S. Besra, "The role of hydrophobicity in tuberculosis evolution and pathogenicity," Sci. Rep., vol. 7, no. 1, p. 1315, 2017.

[10] R. Wood, C. Morrow, C. E. Barry, W. A. Bryden, C. J. Call, A. J. Hickey, C. E. Rodes, T. J. Scriba, J. Blackburn, C. Issarow, N. Mulder, J. Woodward, A. Moosa, V. Singh, V. Mizrahi, and D. F. Warner, "Real-Time Investigation of Tuberculosis Transmission: Developing the Respiratory Aerosol Sampling Chamber (RASC)," PLoS One, vol. 11, no. 1, p. e0146658, Jan. 2016.

[11] J. F. Murray, "The structure and function of the lung," Int. J. Tuberc. Lung Dis., vol. 14, no. 4, pp. 391-396, 2010. 
[12] S. Miyawaki, E. A. Hoffman, and C.-L. Lin, "Effect of static vs. dynamic imaging on particle transport in CT-based numerical models of human central airways," J. Aerosol Sci., vol. 100, pp. 129-139, Oct. 2016.

[13] M. Cantone, G. Santos, P. Wentker, X. Lai, and J. Vera, "Multiplicity of mathematical modeling strategies to search for molecular and cellular insights into bacteria lung infection," Front. Physiol., vol. 8, no. AUG, 2017.

[14] H. S. Jin, H.-M. Lee, D.-H. Lee, G.-H. Cha, K. S. Cho, J. Jang, and E.-K. Jo, "Functional characterisation of the Drosophila cg6568 gene in host defence against Mycobacterium marinum," Microbes Infect., vol. 19, no. 6, pp. 351-357, Jun. 2017.

[15] P.-J. Cardona and C. Prats, "The Small Breathing Amplitude at the Upper Lobes Favors the Attraction of Polymorphonuclear Neutrophils to Mycobacterium tuberculosis Lesions and Helps to Understand the Evolution toward Active Disease in An Individual-Based Model," vol. 7, p. 354, 2016.

[16] E. Marzo, C. Vilaplana, G. Tapia, J. Diaz, V. Garcia, and P.-J. Cardona, "Damaging role of neutrophilic infiltration in a mouse model of progressive tuberculosis.," Tuberculosis, vol. 94, no. 1, pp. 55-64, Jan. 2014.

[17] I. Kramnik and G. Beamer, "Mouse models of human TB pathology: roles in the analysis of necrosis and the development of host-directed therapies," Semin. Immunopathol., vol. 38, no. 2, pp. 221-237, 2016.

[18] W. Hao, L. S. Schlesinger, and A. Friedman, "Modeling Granulomas in Response to Infection in the Lung," PLoS One, vol. 11, no. 3, p. e0148738, Mar. 2016.

[19] E. E. Gray and J. G. Cyster, "Lymph node macrophages," J. Innate Immun., vol. 4, no. 5-6, pp. 424-436, 2012.

[20] C. Vilaplana, C. Prats, E. Marzo, C. Barril, M. Vegué, J. Diaz, J. Valls, D. López, and P.-J. Cardona, "To achieve an earlier IFN- $\gamma$ response is not sufficient to control Mycobacterium tuberculosis infection in mice.," PLoS One, vol. 9, no. 6, p. e100830. [21] S. Marino and D. Kirschner, "A Multi-Compartment Hybrid Computational Model Predicts Key Roles for Dendritic Cells in Tuberculosis Infection," Computation, vol. 4, no. 4, p. 39, Oct. 2016.

[22] C. Ziraldo, C. Gong, D. E. Kirschner, and J. J. Linderman, "Strategic priming with multiple antigens can yield memory cell phenotypes optimized for infection with mycobacterium tuberculosis: A computational study," Front. Microbiol., vol. 6, no. JAN, pp. 1-21, 2016.

[23] C. L. Sershen, S. J. Plimpton, and E. E. May, "Oxygen Modulates the Effectiveness of Granuloma Mediated Host Response to Mycobacterium tuberculosis: A Multiscale Computational Biology Approach," Front. Cell. Infect. Microbiol., vol. 6, no. February, pp. 1-25, 2016.

[24] S. Marino, H. P. Gideon, C. Gong, S. Mankad, J. T. McCrone, P. L. Lin, J. J. Linderman, J. A. L. Flynn, and D. E. Kirschner, "Computational and Empirical Studies Predict Mycobacterium tuberculosis-Specific T Cells as a Biomarker for Infection Outcome," PLoS Comput. Biol., vol. 12, no. 4, pp. 1-30, 2016.

[25] N. Cáceres, G. Tapia, I. Ojanguren, F. Altare, O. Gil, S. Pinto, C. Vilaplana, and P.-J. Cardona, "Evolution of foamy macrophages in the pulmonary granulomas of experimental tuberculosis models.," Tuberculosis (Edinb)., vol. 89, no. 2, pp. 175-82, Mar. 2009.

[26] D. G. Russell, P.-J. Cardona, M.-J. Kim, S. Allain, and F. Altare, "Foamy macrophages and the progression of the human tuberculosis granuloma," Nat. Immunol., vol. 10, 
no. 9, pp. 943-948, Sep. 2009.

[27] H. C. Warsinske, E. Pienaar, J. J. Linderman, J. T. Mattila, and D. E. Kirschner, "Deletion of TGF- $\beta 1$ increases bacterial clearance by cytotoxic $t$ cells in a tuberculosis granuloma model," Front. Immunol., vol. 8, no. DEC, 2017.

[28] H. C. Warsinske, R. M. DiFazio, J. J. Linderman, J. A. L. Flynn, and D. E. Kirschner, "Identifying mechanisms driving formation of granuloma-associated fibrosis during Mycobacterium tuberculosis infection," J. Theor. Biol., vol. 429, pp. 1-17, 2017.

[29] E. Pienaar, W. M. Matern, J. J. Linderman, J. S. Bader, and D. E. Kirschner, "Multiscale model of Mycobacterium tuberculosis infection maps metabolite and gene perturbations to granuloma sterilization predictions," Infect. Immun., vol. 84, no. 5, pp. 1650-1669, 2016.

[30] E. A. Wong, L. Joslyn, N. L. Grant, E. Klein, P. L. Lin, D. E. Kirschner, and J. L. Flynn, "Low levels of T cell exhaustion in tuberculous lung granulomas.," Infect. Immun., no. June, p. IAI.00426-18, 2018.

[31] J. Grosset, "Mycobacterium tuberculosis in the Extracellular Compartment: an Underestimated Adversary", Antimicrobial Agents and Chemotherapy, vol. 47, no. 3, pp. 833-836, 2003.

[32] C. Prats, C. Vilaplana, J. Valls, E. Marzo, P.-J. Cardona, and D. López, "Local Inflammation, Dissemination and Coalescence of Lesions Are Key for the Progression toward Active Tuberculosis: The Bubble Model," Front. Microbiol., vol. 7, no. February, p. 33, 2016.

[33] E. Ibargüen-Mondragón, L. Esteva, and E. M. Burbano-Rosero, "Mathematical model for the growth of Mycobacterium tuberculosis in the granuloma," Math. Biosci. Eng., vol. 15, no. 2, pp. 407-428, 2017.

[34] R. Bowness, M. Chaplain, G. Powathil, and S. Gillespie, "Modelling the effects of bacterial cell state and spatial location on tuberculosis treatment: Insights from a hybrid multiscale cellular automaton model," J. Theor. Biol., vol. 446, pp. 87-100, 2018.

[35] P. L. Lin, P. Maiello, H. P. Gideon, M. T. Coleman, A. M. Cadena, M. A. Rodgers, R. Gregg, M. O'Malley, J. Tomko, D. Fillmore, L. J. Frye, T. Rutledge, R. M. DiFazio, C. Janssen, E. Klein, P. L. Andersen, S. M. Fortune, and J. A. L. Flynn, "PET CT Identifies Reactivation Risk in Cynomolgus Macaques with Latent M. tuberculosis," PLoS Pathog., vol. 12, no. 7, pp. 1-17, 2016.

[36] C. J. Martin, A. M. Cadena, V. W. Leung, L. Lin, P. Maiello, N. Hicks, M. R. Chase, and J. L. Flynn, "Digitally Barcoding Mycobacterium tuberculosis Reveals In Vivo Infection Dynamics in the Macaque Model of Tuberculosis," MBio, vol. 8, pp. e00312-17, 2017.

[37] P.-J. Cardona, "The key role of exudative lesions and their encapsulation: lessons learned from the pathology of human pulmonary tuberculosis.," Front. Microbiol., vol. 6, p. 612, Jan. 2015.

[38] O. Gil, I. Díaz, C. Vilaplana, G. Tapia, J. Díaz, M. Fort, N. Cáceres, S. Pinto, J. Caylà, L. Corner, M. Domingo, and P.-J. Cardona, "Granuloma encapsulation is a key factor for containing tuberculosis infection in minipigs.," PLoS One, vol. 5, no. 4, p. e10030, Jan. 2010.

[39] M. R. Cronan and D. M. Tobin, "Fit for consumption: zebrafish as a model for tuberculosis.," Dis. Model. Mech., vol. 7, no. 7, pp. 777-84, Jul. 2014.

[40] N. Cáceres, I. Llopis, E. Marzo, C. Prats, C. Vilaplana, D. G. de Viedma, S. Samper, D. López, and P.-J. Cardona, "Low Dose Aerosol Fitness at the Innate Phase 
of Murine Infection Better Predicts Virulence amongst Clinical Strains of Mycobacterium tuberculosis," PLoS One, vol. 7, no. 1, p. e29010, Jan. 2012.

[41] M. Datta, L. E. Via, W. Chen, J. W. Baish, L. Xu, C. E. Barry, and R. K. Jain, "Mathematical Model of Oxygen Transport in Tuberculosis Granulomas," Ann. Biomed. Eng., vol. 44, no. 4, pp. 863-872, 2016.

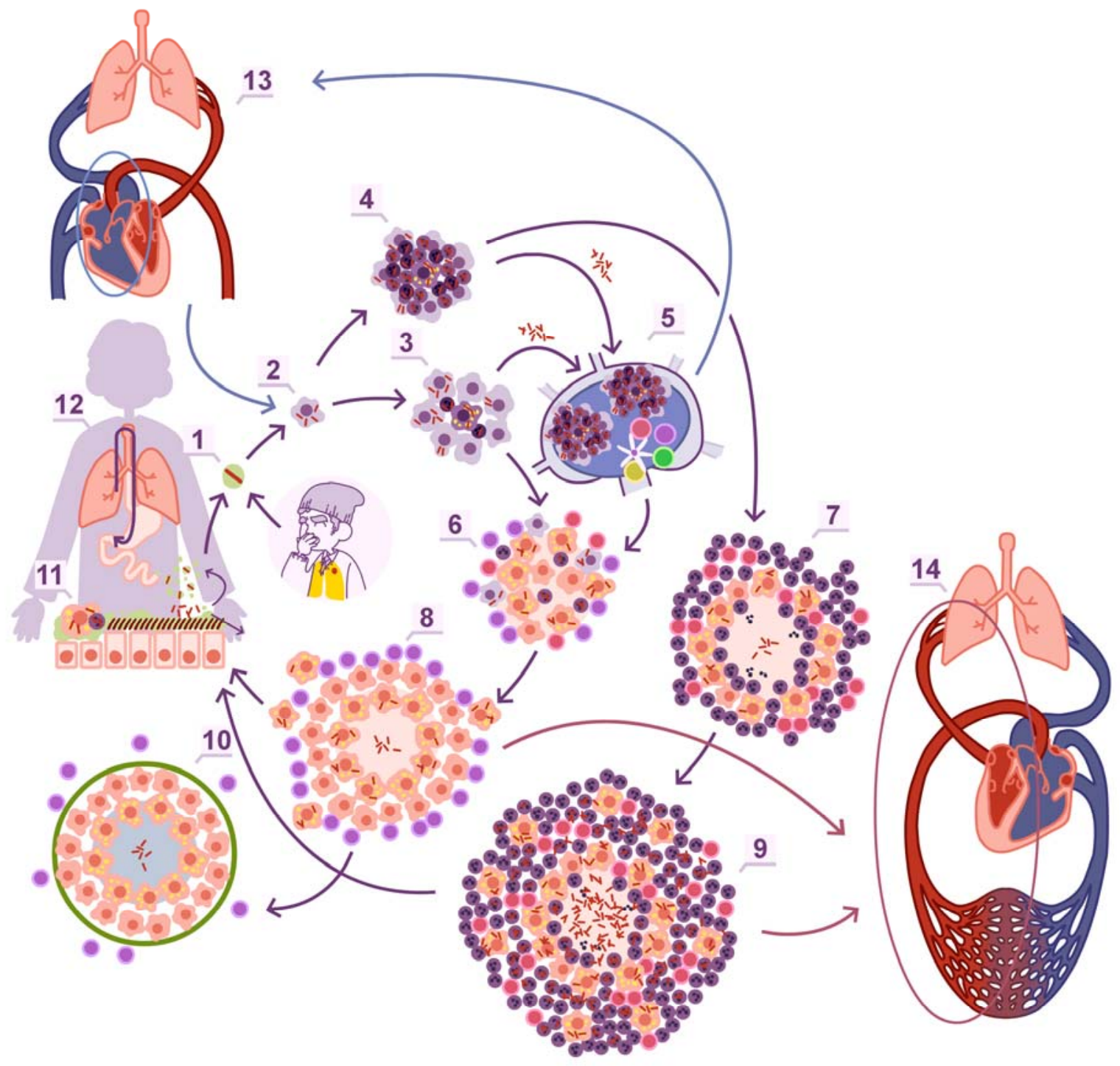

Figure 1. Fourteen steps to frame Mycobacterium tuberculosis immune-modelling

The long road towards the alveoli (1). The interaction at the alveoli (2). The onset of the granuloma, which depending on the infiltration percentage of PMNs can be identified as proliferative (3) or exudative (4) when it is low or high, respectively. The interaction with the regional lymph node (5). Once the adaptive immunity is triggered there is a control in the bacillary load in the case of the proliferative granulomas thanks to a predominium of the Th1 response (6 and 8 ) or a progressive increase thanks to the enhanced entrance of PMNs that allows an extracellular growth of the bacilli ( 7 and 9). Proliferative lesions are rapidly encapsulated (10). In both lesions there is a constant drainage of dormant bacilli carried by foamy macrophages towards the bronchial tree (11) which majoritarily are drained towards 
the gastrointestinal tract (12) but can reenter the lung parenchyma again (1). Systemic reinfection can be done through an over infected lymph node, which drains towards the right heart and it is pumped again into the lung (13), or directly from the lesions, reaching the left heart and being able to induce extrapulmonary lesions (14).

Table 1: Review of the systems biology approaches for the understanding of TB-related issues on the period 2016-2018

\begin{tabular}{|c|c|c|c|c|c|}
\hline Model type & $\begin{array}{l}\text { Uses } \\
\text { GranSim } \\
\text { (yes/no) }\end{array}$ & Main purpose & Main variables & $\begin{array}{c}\text { Steps } \\
\text { totally/partially } \\
\text { considered by } \\
\text { the model }^{*}\end{array}$ & Reference \\
\hline $\begin{array}{l}\text { Agent-based } \\
\text { Model }\end{array}$ & no & $\begin{array}{l}\text { To explore the role of } \\
\text { drainage activity, } \\
\text { encapsulation, } \\
\text { macrophage tolerability } \\
\text { to bacillary load and } \\
\text { quality of the immune } \\
\text { response on the lesions' } \\
\text { patterns }\end{array}$ & $\begin{array}{l}\text { Interstitial and resident } \\
\text { alveolar macrophages, } \\
\text { activated macrophages, } \\
\text { neutrophils, intracellular } \\
\text { bacilli, growing and non- } \\
\text { growing extracellular } \\
\text { bacilli, dormant bacilli, } \\
\text { fibroblasts }\end{array}$ & $\begin{array}{c}2,3,4,6,7,8,9,10 \\
11\end{array}$ & [15] \\
\hline $\begin{array}{l}\text { Convection- } \\
\text { diffusion } \\
\text { partial } \\
\text { differential } \\
\text { equations }\end{array}$ & no & $\begin{array}{l}\text { To evaluate the efficacy } \\
\text { of anti IL-10 and anti IL- } \\
13 \text { treatments }\end{array}$ &  & $3,5,6$ & [18] \\
\hline $\begin{array}{l}\text { Multi- } \\
\text { compartmen } \\
\text { t hybrid } \\
\text { model } \\
\text { (including } \\
\text { ABM, PDEs, } \\
\text { ODEs) } \\
\end{array}$ & yes & $\begin{array}{l}\text { To study antigen } \\
\text { presentation, T cell } \\
\text { priming, differentiation } \\
\text { and trafficking in the } \\
\text { context of TB granuloma } \\
\text { formation }\end{array}$ & $\begin{array}{l}\text { Macrophages, T cells, } \\
\text { bacilli, cytokines and } \\
\text { chemokines, dendritic } \\
\text { cells }\end{array}$ & $3,5,6$ & [21] \\
\hline $\begin{array}{l}\text { Multi- } \\
\text { compartmen } \\
\text { t hybrid } \\
\text { model } \\
\text { (including } \\
\text { ABM, PDEs, } \\
\text { ODEs) }\end{array}$ & yes & $\begin{array}{l}\text { To explore how } \\
\text { properties of LN } \\
\text { environmental } \\
\text { conditions, T cells and } \\
\text { antigens affect the } \\
\text { amounts and types of } \\
\text { memory T cells, as well } \\
\text { as successive } \\
\text { vaccinations }\end{array}$ & $\begin{array}{l}\text { Ag-specific naïve T cells, } \\
\text { central memory T cells, } \\
\text { effector memory T cells, } \\
\text { dendritic cells, effector } \\
\text { cells, macrophages, } \\
\text { bacilli, chemokines, } \\
\text { cytokines, and other } \\
\text { soluble ligands }\end{array}$ & $3,5,6$ & {$[22]$} \\
\hline $\begin{array}{l}\text { Integrated } \\
\text { Multiscale } \\
\text { Model }\end{array}$ & no & $\begin{array}{l}\text { To demonstrate how } \\
\text { hypoxia can occur in the } \\
\text { human response to } \\
\text { granuloma formation }\end{array}$ & $\begin{array}{l}\text { Macrophages and T cells } \\
\text { as particles, oxygen, } \\
\text { chemokines; cytokines } \\
\text { and bacilli as field } \\
\text { variables }\end{array}$ & $3,6,14$ & [23] \\
\hline
\end{tabular}




\begin{tabular}{|c|c|c|c|c|c|}
\hline $\begin{array}{l}\text { Multi-scale } \\
\text { hybrid model } \\
\text { (including } \\
\text { ABM, PDEs, } \\
\text { ODEs) }\end{array}$ & yes & $\begin{array}{l}\text { To show that pairing } \\
\text { computer modeling, } \\
\text { statistics and } \\
\text { mathematics with } \\
\text { datasets derived from } \\
\text { non-human primate } \\
\text { studies can accelerate } \\
\text { biomarker discovery }\end{array}$ & $\begin{array}{l}\text { Macrophages, T cells, } \\
\text { bacilli, cytokines and } \\
\text { chemokines }\end{array}$ & $3,5,6,13$ & [24] \\
\hline $\begin{array}{l}\text { Multi-scale } \\
\text { hybrid model } \\
\text { (including } \\
\text { ABM, PDEs, } \\
\text { ODEs) }\end{array}$ & yes & $\begin{array}{l}\text { To investigate the } \\
\text { regulatory role of TGF- } \\
\beta 1 \text { in granulomas' } \\
\text { control }\end{array}$ & $\begin{array}{l}\text { Macrophages (resting, } \\
\text { activated, infected, and } \\
\text { chronically infected), T- } \\
\text { cells (cytotoxic, } \\
\text { inflammatory, } \\
\text { regulatory), bacilli, } \\
\text { cytokines and } \\
\text { chemokines }\end{array}$ & 3,6 & [27] \\
\hline $\begin{array}{l}\text { Multi-scale } \\
\text { hybrid model } \\
\text { (including } \\
\text { ABM, PDEs, } \\
\text { ODEs) }\end{array}$ & yes & $\begin{array}{l}\text { To elucidate the } \\
\text { dynamics that lead to } \\
\text { fibrosis identifying } \\
\text { factors that distinguish } \\
\text { central and peripheral } \\
\text { fibrosis and the role of } \\
\text { cytokines and cells }\end{array}$ & $\begin{array}{l}\text { Fibroblasts, } \\
\text { myofibroblasts, } \\
\text { macrophages (resting, } \\
\text { activated, infected, and } \\
\text { chronically inected), T } \\
\text { cells (cytotoxic, } \\
\text { inflammatory, } \\
\text { regulatory), bacilli, } \\
\text { cytokines and } \\
\text { chemokines (IL10, TGF- } \\
\beta 1, \text { TNF } \alpha . . .), \text { collagen }\end{array}$ & $3,6,10$ & [28] \\
\hline $\begin{array}{l}\text { Multi-scale } \\
\text { hybrid model } \\
\text { (including } \\
\text { ABM, PDEs, } \\
\text { ODEs) }\end{array}$ & yes & $\begin{array}{l}\text { To address the bacterial } \\
\text { phenotypes emergence } \\
\text { and their role on the } \\
\text { granuloma dynamics } \\
\text { and to predict the } \\
\text { potential of in vitro } \\
\text { screening to identify } \\
\text { bacterial metabolic } \\
\text { targets for treatment of } \\
\text { TB }\end{array}$ & $\begin{array}{l}\text { Macrophages (resting, } \\
\text { activated, infected, and } \\
\text { chronically infected), T- } \\
\text { cells (cytotoxic, } \\
\text { inflammatory, } \\
\text { regulatory), bacilli, } \\
\text { cytokines and } \\
\text { chemokines, other } \\
\text { compounds (oxygen, } \\
\text { glucose, triacylglycerol) }\end{array}$ & $3,6,14$ & [29] \\
\hline $\begin{array}{l}\text { Multi-scale } \\
\text { hybrid model } \\
\text { (including } \\
\text { ABM, PDEs, } \\
\text { ODEs) }\end{array}$ & yes & $\begin{array}{l}\text { To explore the role of } \\
\text { low T cell exhaustion on } \\
\text { TB granulomas }\end{array}$ & $\begin{array}{l}\text { Macrophages (resting, } \\
\text { activated, infected, and } \\
\text { chronically infected), T- } \\
\text { cells (cytotoxic, } \\
\text { inflammatory, } \\
\text { regulatory), bacilli, } \\
\text { cytokines and } \\
\text { chemokines }\end{array}$ & $3,6,14$ & [30] \\
\hline $\begin{array}{l}\text { Agent-based } \\
\text { Model }\end{array}$ & no & $\begin{array}{l}\text { To study the role of } \\
\text { lesions coalescence as } \\
\text { an essential growth } \\
\text { factor in active TB }\end{array}$ & $\begin{array}{l}\text { Lesions' size, age and } \\
\text { position }\end{array}$ & $4,7,9$ & [32] \\
\hline $\begin{array}{l}\text { Non-linear } \\
\text { system of } \\
\text { ordinary } \\
\text { differential } \\
\text { equations }\end{array}$ & no & $\begin{array}{l}\text { To assess the impact of } \\
\text { the competition among } \\
\text { intracellular and } \\
\text { extracellular bacteria on } \\
\text { the infection prevalence }\end{array}$ & $\begin{array}{l}\text { Non-infected } \\
\text { macrophages, infected } \\
\text { macrophages, bacilli and } \\
\text { T-cells }\end{array}$ & 3,6 & [33] \\
\hline
\end{tabular}




\begin{tabular}{|c|c|c|c|c|c|}
\hline \multirow[b]{2}{*}{$\begin{array}{c}\text { Hybrid } \\
\text { cellular } \\
\text { automaton }\end{array}$} & \multirow[b]{2}{*}{ no } & & \multirow[b]{2}{*}{$\begin{array}{l}\text { Bacilli, macrophages and } \\
\text { T cells; oxygen, drugs } \\
\text { and chemokines }\end{array}$} & \multirow[b]{2}{*}{$3,6,14$} & \multirow[b]{2}{*}{ [34] } \\
\hline & & $\begin{array}{l}\text { To investigate the role of } \\
\text { bacterial cell state and } \\
\text { of initial bacterial } \\
\text { location (distance to } \\
\text { blood vessels) on } \\
\text { treatment outcome }\end{array}$ & & & \\
\hline $\begin{array}{l}\text { Reaction- } \\
\text { diffusion } \\
\text { model }\end{array}$ & no & $\begin{array}{l}\text { To offer a predictive tool } \\
\text { for characterizing } \\
\text { oxygen concentration } \\
\text { profiles and the amount } \\
\text { of hypoxia and necrosis }\end{array}$ & Oxygen concentration & 8 & [41] \\
\hline
\end{tabular}

${ }^{*}$ See Figure 1 for details: 1 . The long road towards the alveoli; 2 . The interaction at the alveoli; $3 \& 4$. The onset of the granuloma, that may be proliferative (3) or exudative (4); 5 . The interaction with the regional lymph node; $6 \& 8$. Control in the bacillary load in proliferative granulomas thanks to a predominium on the Th1 response; $7 \& 9$. Progressive extracellular increase in the bacillary load thanks to an enhanced entrance of PMNs; 10 . Encapsulation of proliferative lesions; 11. Drainage of dormant bacilli inside foamy macrophages towards the bronchial tree; 12. Drainage towards the gastrointestinal tract; $13 \& 14$. Systemic reinfection through an over infected lymph node (13) or directly from the lesions (14). 